\title{
CULTURA, PATRIMÔNIO E TERRITÓRIOS DO VINHO
}

\author{
Culture, Patrimony and Wine Territory \\ Culture, Patrimoine et Territoire du Vin
}

Rosa Maria Vieira Medeiros ${ }^{*}$

*Universidade Federal do Rio Grande do Sul - rmvmedeiros@ufrgs.br

Versão online publicada em 25/02/2022 (http://seer.ufrgs.br/paraonde)

Como citar esse artigo: MEDEIROS, R. M. V. Cultura, patrimônio e territórios do vinho. Para Onde!?, v. 16, n. 1, p. 01-08, 2022.

\section{Resumo:}

A vitivinicultura no Brasil já é uma realidade dada sua expansão e seu reconhecimento na produção de vinhos finos. A Indicação Geográfica (Indicação de Procedência, Denominação de Origem) obtidas em diversos territórios vitivinícolas brasileiros consolidou a importância dessa produção. No que tange a vitivinicultura, foi um processo construído pelo sentimento identitário dos imigrantes que chegaram ao Brasil, mais precisamente no Rio Grande do Sul, no século XIX. A expansão das áreas de produção em todo o território nacional vem ocorrendo com produção de qualidade e com competitividade em relação à produção vinícola internacional. Nesse sentido, busca-se entender a expressão da vitivinicultura como forma de preservar a memória, a cultura e o patrimônio do vinho no Brasil.

Palavras-chave: Vitivinicultura. Identidade. Patrimônio.

\begin{abstract}
:
Viticulture in Brazil is already a reality given its expansion and recognition in the production of fine wines. The Geographical Indication (Indication of Origin, Designation of Origin) obtained in several Brazilian wine-growing territories has consolidated the importance of this production. As for viticulture, it was a process built by the sense of identity of immigrants who arrived in Brazil, more precisely in the Rio Grande do Sul, in the 19th century. The expansion of production areas over the whole of the national territory has occurred through quality production and competitiveness in relation to international wine production. In this sense, we try to understand the expression of viticulture as a means of preserving the memory, culture and heritage of wine in Brazil.
\end{abstract}

Keywords: Viticulture. Identity. Heritage. 


\section{Résumé:}

La viticulture au Brésil est déjà une réalité étant donné son expansion et sa reconnaissance dans la production de vins fins. L'Indication Géographique (Indication de Provenance, Appellation d'Origine) obtenue dans plusieurs territoires vitivinicoles brésiliens a consolidé l'importance de cette production. En ce qui concerne la viticulture, c'était un processus construit par le sentiment identitaire des immigrants qui sont arrivés au Brésil, plus précisément dans le Rio Grande do Sul, au XIX siècle. L'expansion des zones de production sur l'ensemble du territoire national s'est produite par une production de qualité et compétitivité par rapport à la production vinicole internationale. En ce sens, on cherche à comprendre l'expression de la viticulture comme moyen de préserver la mémoire, la culture et le patrimoine du vin au Brésil.

Mots-clés : vitiviniculture, identité, patrimoine.

\section{INTRODUÇÃO}

A vitivinicultura brasileira teve início em São Paulo, na então Vila de São Paulo, conforme registro de Gabriel Soares de Souza no Tratado Descritivo do Brasil em 1587: "[...] os moradores da vila de São Paulo têm já muitas vinhas; e há homens nela que colhem já duas pipas de vinho por ano, e por causa das plantas é muito verde, e para se não avinagrar lhe dão uma fervura no fogo" (SOUZA, 1587).

No Estado do Rio Grande do Sul, a videira foi introduzida por volta de 1626 pelo jesuíta, natural de Buenos Aires, Roque Gonzáles que, em São Nicolau, na fase que antecedeu os Sete Povos das Missões, plantou videiras (VALDUGA, 2011). A hipótese mais simples daria conta de que, nesse caso, as vinhas do Rio Grande do Sul teriam origem espanhola, já que as vinhas argentinas teriam essa origem ou então, os portugueses teriam introduzido, trazendo-as dos Açores. Rabuske (1979) detalha aspectos da produção e processos de vinificação registrados pelo padre Antonio Sepp, da Redução de São José ${ }^{1}$. Nele são descritas as melhores uvas e vinhas para elaboração dos vinhos e fases da produção. "[...] O mosto ou sumo, estando já frio, põe-se na garrafa sem enchê-la para que possa fermentar, o que dura oito dias, e depois se fecha a garrafa com um pedaço de telha, e gesso e um couro fresco bem atado" (RABUSKE, 1979, p. 36).

Uma descrição da produção também foi feita pelo botânico Auguste de SaintHilaire na "Viagem ao Rio Grande do Sul", que cita a produção de uvas nos arredores de Porto Alegre, São José do Norte e llha dos Marinheiros, um pouco mais tarde, por volta de 1820 (SAINT-HILAIRE, 1974).

As uvas produzidas no Rio Grande do Sul inicialmente foram de origem vitis vinífera, já que o Brasil não tem variedades nativas e as uvas de origem norteamericana foram introduzidas posteriormente. Segundo Sousa (1969), a introdução da uva Isabel ocorreu entre os anos de 1839 a 1842, quando o gaúcho Marques Lisboa remeteu de Washington, bacelos consignados ao comerciante Thomaz Messiter, que formou com eles os primeiros vinhedos da Ilha dos Marinheiros, em Rio Grande.

Os imigrantes alemães, que chegaram ao estado por volta de $1824 \mathrm{e}$ foram

\footnotetext{
${ }^{1}$ Imediações das atuais cidades de Bela Vista do Paraíso e Sertanópolis, no Paraná.
} 
assentados nas margens do rio dos Sinos, cultivaram as primeiras vinhas mais próximas à zona de colonização italiana, que chegaria somente a partir de 1875 para colonizar a encosta do planalto do RS. O vinho era o principal produto importado pelo Brasil colônia e sua importação atendia à demanda da elite econômica e cultural na época. A importação de vinhos somente começou a declinar depois de 1850, a partir da chegada de imigrantes italianos, inicialmente em São Paulo para o trabalho nas lavouras de café e, posteriormente, a partir de 1875 ao Rio Grande do Sul. Esses imigrantes começaram a cultivar videiras em maior escala.

As correntes imigratórias do RS tentaram desenvolver a vitivinicultura, como os franceses em Garibaldi e Pelotas e os alemães, na região central do estado e vale do rio Caí. Pellanda (1950, p. 53) relata que, na Capitania, o capitãomor, Manoel Bento da Rocha, fabricava em Pelotas de 5 a 6 pipas e Manuel Macedo, em Rio Pardo, chegou a produzir 15 pipas num ano, "merecendo honrosa provisão da Junta de Comércio do Rio de Janeiro". Cita que os imigrantes renanos trouxeram alguma tradição enológica da Alemanha, entretanto assim como ocorreria mais tarde com os italianos, houve dificuldades de aclimatação das videiras europeias. Pesavento (1983) refere que, na exposição Provincial ocorrida em Porto Alegre, em 1875, colonos alemães compareceram com amostras de vinho tinto e branco, engarrafado e em barril. Compareceram também alguns expositores de origem luso-brasileira, sediados em Porto Alegre, que fabricavam vinho nacional. Essa produção era baseada na unidade familiar, produzida no lote colonial de forma artesanal.

A vitivinicultura estadual e nacional tem um contexto geográfico e histórico muito particular, com muita riqueza social e cultural. No entanto, há pouca pesquisa relacionada aos aspectos culturais e patrimoniais da vitivinicultura, 0 que representa um ponto central para o entendimento de todo desenvolvimento da vitivinicultura nacional. O patrimônio do vinho no Brasil está se deteriorando, a exemplo de uma das primeiras vinícolas formais do Brasil, a J. Marimon e Filhos, registrada em 1880 na Fazenda do Seival, em Bagé/RS.

Com relação à produção vinícola no Estado do Rio Grande do Sul, esta representa mais de $90 \%$ da produção brasileira. Envolve uma cadeia produtiva aproximada de 16 mil famílias vinculadas direta ou indiretamente às mais de 600 vinícolas do estado. Contudo, a carência de dados quantitativos da vitivinicultura do estado e do Brasil é uma realidade, há falhas nesse processo e existem disparidades entre dados divulgados por diversos órgãos como Instituto Brasileiro do Vinho, Embrapa Uva e Vinho e Ministério da Agricultura. Da mesma maneira, pode-se dizer que desde a abertura comercial brasileira, em meados dos anos 1990, a vitivinicultura passa por ciclos diversos, de maneira muito mais vulnerável ao avanço comercial de países produtores concorrentes.

No contexto das regiões vinícolas brasileiras destaca-se o Vale dos Vinhedos, região situada entre os municípios de Bento Gonçalves, Garibaldi e Monte Belo do Sul. Essa foi a primeira região do Brasil a obter uma Indicação Geográfica de Procedência (IP) para produtos de origem agroindustrial em 2002 e a primeira a obter a certificação de Denominação de Origem (DO), em

ParaOnde!?, Porto Alegre, v.16 n.2, p.01-09, 2022. http://seer.ufrgs.br/paraonde 
2009. Ao mesmo tempo é a principal região de enoturismo do Brasil, sendo o Vale dos Vinhedos escolhido como um dos 10 destinos de enoturismo mais importantes do mundo pela revista estadunidense Wine Enthusiast em 2013.

A vitivinicultura no estado do Rio Grande do Sul se expande a passos largos também na metade sul do estado, com destaque aos municípios de Alegrete, Bagé, Candiota, Dom Pedrito, Itaqui, Maçambará, Quaraí, Rosário do Sul, Sant'Ana do Livramento, Uruguaiana, Pinheiro Machado e Encruzilhada do Sul. Fora do Estado há uma expansão qualitativa e quantitativa importante, especialmente nas regiões do meio oeste catarinense, região metropolitana de Curitiba, Minas Gerais e no Nordeste brasileiro, compondo uma nova configuração para a vitivinicultura do país.

\section{CULTURA, VINHO E PATRIMÔNIO}

O crescente desenvolvimento da vitivinicultura brasileira faz com que haja a necessidade premente de geração e de difusão de conhecimento interdisciplinar no campo da Cultura e do Patrimônio do Vinho. A cadeia produtiva da uva e do vinho no Brasil abrange diferentes áreas técnicas, com ênfase em biotecnologia, enologia e manejo de solos, constituindo áreas fundamentais para a vitivinicultura. No entanto, outros aspectos dessa cadeia produtiva precisam ser contemplados, sobretudo aqueles relacionados à cultura, às paisagens vitivinícolas, à geografia e à história do vinho, ao enoturismo, ao mercado consumidor e ao desenvolvimento da vitivinicultura.

Nesse sentido, é fundamental demonstrar a constituição do território do vinho e sua relação cultural/identitária com a paisagem e por consequência com o patrimônio. Esse patrimônio, embora concreto, se perpetua na memória de uma coletividade com sua subjetividade, seu sentido e sua experiência enquanto que o território, segundo Bonnemaison, (2000) é o espaço da identidade, da identificação e, segundo Saquet (2000), é o espaço apropriado política e culturalmente, para a formação de uma identidade regional e cultural/política.

Mas como compreender essa relação identitária do vinho com o território? Como é construída a identidade do vinho? O vinho pode ser um argumento de identidade para o território?

Segundo Medeiros (2015), este é o território, que se constituirá como um espaço cultural de identificação, de pertencimento, mas ao mesmo tempo um espaço político, um lugar do poder onde as ações atendem demandas políticas, econômicas e sociais. Há nesse território um sentimento de pertencimento que contribuirá para a sua valorização.

Maby (2007), por sua vez considera que o espaço o qual é o lugar de origem de um vinho é a garantia de sua identidade e de sua autenticidade. $\mathrm{Na}$ viticultura o princípio identitário se apoia no "direito do solo" e as características genéticas do indivíduo "vinho" são atributos essencialmente geográficos. Com isso, o produto é autenticado como "cru"2, ou seja, como um produto no qual a

${ }^{2}$ Os crus são classificações específicas para cada região francesa. A expressão CRU significa

ParaOnde!?, Porto Alegre, v.16 n.2, p.01-09, 2022. http://seer.ufrgs.br/paraonde 
identidade está condicionada ao fato de "crescer" em um determinado lugar. Além do mais, o território é o lugar onde se realiza a "permanência de usos". (MABY, 2007, p.4) ${ }^{3}$.

É este território com usos, costumes e modos de vida que são constantes e que se repetem ao longo do tempo, que Gui Di Méo (1998) define como espaço vivido. Este espaço vivido é impregnado de valores culturais que refletem o sentimento de pertencimento de cada indivíduo em relação a um determinado grupo. Maby (2007) afirma que a sede do vinho de terroir ${ }^{4}$ é uma sede de identidade espacial que pode ser, atualmente, relacionada às identidades geográficas como "uma inextinguível sede ontológica". Significa que o homem não pode viver de forma indiferente num espaço, ele vai transformar este espaço no sentido de se sentir inserido, de ser parte integrante do mesmo.

O espaço, portanto, como portador de valores socioculturais atua no sentido de enriquecer a identidade do vinho. O vinho de terroir é um produto duplamente territorializado, pois ao mesmo tempo em que está inscrito em um território real, ele também faz parte de toda a pressão territorial ambiental. $\mathrm{O}$ sistema vitivinícola dá conta de ambos, assim como das restrições relativas aos processos de produção e às formas de organização social. A identidade territorial é, portanto, indissociável da identidade de seus componentes tais como serviços, bens de troca, infraestruturas, qualidades sociais e natureza. $O$ vinho necessita da identidade assim como o território, que também necessita de sua identidade, mas identidades que abranjam pelo menos aquelas que significam "ser" do território. Ocorre então em diferentes níveis, uma interação identitária vinho/território, mas é somente sobre alguns temas precisos que ela assume um nível que possibilita ao território receber pelo menos tanto quanto ele oferece. Destaca-se aqui a paisagem, o patrimônio e a cultura como os domínios que mobilizam os recursos do meio na relação vinho/território.

Segundo a UNESCO (2003), há uma imaterialidade presente no patrimônio que foi socialmente construído, que se expressa nas práticas das comunidades, na sua história, na transmissão de conhecimentos e saberes através das gerações. São elementos reconhecidos como patrimônio cultural que apresentam forte relação com a natureza e com a identidade. Essa

uma classificação ainda superior, ligada à noção de qualidade. O termo CRU, se aplica unicamente aos vinhos AOP(s) - Apelação de Origem Controlada (DESCUBRA A FRANÇA, 2019).

${ }^{3}$ L'espace comme lieu d'origine d'un vin est le garant de son identité et de son authenticité. En viticulture le principe identitaire relève du « droit du sol » et les caractères génétiques de 'individu "vin " sont des attributs essentiellement géographiques. Ainsi le produit est-il authentifié en tant que " cru », c'est-à-dire en tant que produit dont l'identité est conditionnée par le fait de «croître » en un lieu donné. De plus le territoire est le lieu où se réalise la « constance des usages » (CONFERENCE DONNEE A LA SOCIETE GEOGRAPHIQUE ITALIENNE, 2007).

4 O "terroir" vitícola é um conceito que se refere a um espaço sobre o qual se desenvolve um conhecimento coletivo das interações entre um ambiente físico e biológico identificável e as práticas vitivinícolas aplicadas, as quais conferem características distintas aos produtos oriundos desse espaço. O "terroir" inclui características específicas de solo, topografia, clima, paisagem e biodiversidade. 
imaterialidade se expressa na linguagem, nas artes, nas práticas, nas festas, na tradição e que enraíza e reúne aqueles que compartilham do mesmo sentimento na construção de um caminho identitário comum.

Portanto, nessa relação território, paisagem e patrimônio busca-se inicialmente o conceito de paisagem. De acordo com Santos (1996), a paisagem é a sobreposição, ou seja, uma paisagem é escrita sobre a outra para assim formar um conjunto de objetos com diferentes idades que representam a herança de tempos passados. A paisagem é a soma de peças de tempos históricos que representam diferentes maneiras de produzir coisas, de construir espaço. Já Silva (1991), conceitua paisagem como o lugar social percebido e entendido, que expressa ações, relações assim como objetos sociais. São as intervenções humanas na natureza que transformam a paisagem em cultura, logo todas as paisagens contêm significados simbólicos enquanto produtos da apropriação e transformação da natureza pelo homem. É a dimensão sensível, estética e afetiva da relação que o indivíduo socializado constrói e reconstrói com o território. Para Berque (1998), o estudo da paisagem é mais que uma psicologia do olhar, muito embora represente ou evoque o imaginário ela tem um suporte indubitavelmente objetivo.

A paisagem é tão complexa quanto o vinho, ela é viva, é o resultado da história e das práticas encontradas e identificadas. O encontro do homem com a paisagem se dá a partir de percepções assim como o encontro do homem com o vinho, que construiu um quadro de vida identitário caracterizando as paisagens vitícolas. A paisagem é a testemunha do sentimento de pertencimento, da cultura e das tradições. O vinhedo é o agente transformador da paisagem, marca o território e é o símbolo da cultura local e do patrimônio. O vinhedo, o vinho e as pessoas deste território estão circunscritas na paisagem. No sabor do vinho está o território, o trabalho e a cultura daqueles que o elaboraram. O território do vinho está marcado pela paisagem vitícola construída pela tradição, pelos saberes e luta pela preservação de seu patrimônio histórico e cultural. Território, identidade, paisagem e patrimônio tem o vinho como elemento comum e de acordo com Maby (2007), assim como não há vinho sem fala ou identidade sem voz não há geografia sem palavras. $O$ milagre do vinho é, portanto, o milagre da vida e o vinho que leva as promessas e a alegria terrena naturalmente usará o mesmo simbolismo no pensamento secular, como se a secularização desse imaginário se referisse imediatamente a uma arte de viver (Maby,2007).

Assim, a cultura e a memória do vinho podem ser também vislumbradas pelas paisagens registradas a partir de fotografias antigas e recentes, sendo possível perceber as transformações materiais e imateriais. Dessa forma, ao considerar a vitivinicultura como agente das transformações, vê-se a expressão de uma cultura sedimentada no território.

Associado a essa expansão dos territórios do vinho, um novo elemento se faz presente de forma marcante, o enoturismo, também relacionado ao desenvolvimento local considerando os fluxos de origem e a sua densidade. Todos esses elementos são efetivamente relacionados aos aspectos sociais, econômicos e políticos dos municípios produtores marcados por seu terroir 
vitivinícola.

\section{CONSIDERAÇÕES FINAIS}

Ao entender a vitivinicultura como forma de preservar a memória, a cultura e o patrimônio do vinho no Brasil temos aqui, um outro impacto no conhecimento relacionado à vitivinicultura e à sua relação com o território, com o patrimônio e com a paisagem.

Isso pode contribuir de forma significativa na delineação de políticas públicas voltadas ao reconhecimento da paisagem vitivinícola enquanto patrimônio. Esse reconhecimento fortalece o território do vinho para odesenvolvimento do enoturismo, possibilita as práticas agrícolas associadas à preservação da natureza, auxilia no reconhecimento do vinho como alimento, além de trazer benefícios à agricultura familiar produtora de uva e vinho.

Portanto, urge a necessidade de pesquisa, preservação da memória, da cultura e do patrimônio do vinho, sob pena de se perder no tempo e no espaço, sem que as futuras gerações conheçam sua própria história e sua memória. As pesquisas relacionadas à vitivinicultura no Brasil comumente referem-se e limitam-se aos aspectos técnicos de produção, enologia e vitivinicultura, o que é tão importante quanto a pesquisa relacionada ao patrimônio cultural do vinho, ao consumidor, à ética, às formas de gestão vitivinícola, entre outras temáticas relacionadas.

O grande desafio, portanto, além de encontrar ao vocação do terroir é apostar na modernidade sem abandonar os saberes, as tradições. A identidade deve ser fortalecida na sua constituição histórica e patrimonial o que, certamente e cada vez mais, qualificará o vinho.

São as paisagens vitícolas, de rara beleza, que devem permanecer vivas enquanto expressão identitária e patrimonial, com suas mudanças controladas a fim de evitar destruições irremediáveis.

\section{REFERÊNCIAS}

BONNEMAISON, Joel. La géographie culturelle (établi par Maud Lasseur et Christel Thibault). Paris, éditions du CTHS, 2000.

CONFÉRENCE DONNÉE À LA SOCIÉTÉ GÉOGRAPHIQUE ITALIENNE. Le vin, argument identitaire du territoire. Disponível em: https://jacquesmaby.wordpress.com/2007/01/13/le-vin-argument-identitairedu-territoire/. Acesso em: 05 mar. 2019.

DESCUBRA A FRANÇA. Vinhos franceses, conheça a classificação. Disponivel em: http://descubraafranca.com.br/vinhos-franceses/. Acesso em : 05 mar. 2019.

Di MÉO, Gui. Les territoires du quotidien. Paris, L'Harmattan, 1996, 208 p. 
MABY, Jacques. Conférence donnée à la Société Géographique Italienne. Rome, $2007 . \quad$ Disponível em: https://jacquesmaby.wordpress.com/2007/01/13/le-vin-argument-identitairedu-territoire/. Acesso em: 05 mar.2019.

MEDEIROS, Rosa Maria Vieira. Território espaço de identidade. In SAQUET, Marco Aurélio; SPOSITO, Eliseu Savério (Orgs.). Territórios e territorialidades: teorias, processos e conflitos. Rio de Janeiro, Editora Consequência, 2015.

PELLANDA, Ernesto. Aspectos gerais da colonização italiana no Rio Grande do Sul. In: BERTASO, Henrique D.; LIMA, Mário de A. (Orgs.). Álbum comemorativo do $75^{\circ}$ aniversário da colonização italiana no Rio Grande do Sul. Porto Alegre: Revista do Globo, 1950. p. 33-64.

PESAVENTO, Sandra J. RS: agropecuária colonial e industrialização. Porto Alegre: Mercado Aberto, 1983.

RABUSKE , Arthur. Padre Antonio Sepp: o gênio das reduções Guaranis. São Leopoldo, Unisinos, 1979.

SAINT-HILAIRE, Auguste de. Viagem ao Rio Grande do Sul: 1820-182. Belo Horizonte: Itatiaia, 1974.

SAQUET, Marcos A. O tempo, o espaço e o território. In SOUZA, Álvaro José de; SOUZA, Edson Belo Clemente de; JUNIOR, Lourenço Magnoni (Orgs) Paisagem, Território, Região: em busca da identidade. EDUNIOESTE, Cascavel, 2000, p.103-114.

SOUZA, Gabriel S. de. Tratado descritivo do Brasil em 1587. Disponível em: $<$ https://www.dominiopublico.gov.br/dowload/texto/me003015.pdf>. Acesso em: 15 nov. 2014.

SOUSA. Julio S. Inglez de. Origens do vinhedo paulista. Prefeitura Municipal de Jundiaí: Jundiaí, 1959

UNESCO, 2003.2 Disponível em: <http://unesdoc.unesco.org/images/0013/001325/132540por.pdf>.

VALDUGA, V. Enoturismo no Vale dos Vinhedos. Fundação Universidade Federal do Pampa. Jaguarão, 2011.

WINE ENTHUSIAST. Disponível em: http://www. winesofbrasil.com/PressReleases.aspx?id=148. Acesso em: 22 no. 2014. 